\title{
Nivel de conocimiento sobre los efectos de los juegos online en los estudiantes del primer año de educación secundaria
}

\author{
Calle-Sarmiento Rosario ${ }^{1}$, Tafur-Núñez Trinidad ${ }^{1}$, Ruiz-Huamán Katherine¹, Villar-Prado Sabina²
}

\section{RESUMEN}

Objetivo: determinar el nivel de conocimiento sobre los efectos de los juegos online en los estudiantes del primer año de educación secundaria de la Institución Educativa de acción conjunta San Pedro Santísima Trinidad de Lurín. Material y métodos: estudio descriptivo de corte transversal; la muestra fue de 155 estudiantes. Para la recolección de datos se utilizó un cuestionario validado por juicio de expertos y estructurado con preguntas cerradas y de elección múltiple. Resultados: el nivel de conocimiento de los efectos de los juegos online que predominó fue el nivel medio y bajo con un $76,8 \%$, en contraste con el $23,2 \%$ que presentó nivel de conocimiento alto. El nivel de conocimiento fue medio en ambos sexos, siendo del 50,0\% para el sexo femenino y del 53,2\% para el sexo masculino. Según edad, el nivel de conocimiento fue medio en el 50\% de los estudiantes de 11 años; 53,8\% en los estudiantes de 12 años y 44,1\% en los estudiantes de 13 años de edad. Con respecto al número de horas de uso de los juegos online, se obtuvo que el 44,4\% utiliza más de $30 \mathrm{~h}$ a la semana, tiene un nivel de conocimiento bajo y el 33,3\% un nivel de conocimiento medio. Conclusiones: existe un alto porcentaje de estudiantes que no conoce los efectos físicos, psicológicos y sociales del uso de los juegos online.

Palabras clave: conocimiento, juegos, internet. Perú. (Fuente DeCs BIREME).

\section{Knowledge about the effects of online games on students in the first year of secondary education}

\begin{abstract}
Objetive: The purpose of this study was to determine the level of knowledge about the effects of online games in the students in 1st year of secondary education of educational institution educative joint action San Pedro Santísima Trinidad de Lurín. Material and Methods: of study: the study was cross sectional, the sample was 155 students. Data collection: the questionnaire was validated by experts and structured with closed questions and multiple choices. Results: The level of knowledge of the effects of online gaming was the predominant medium and low with 76.8\%, compared to $23.2 \%$ that showed a high level of knowledge. According to gender the knowledge level of dominance, in both genders was the means, being $50.0 \%$ for females and $53.2 \%$ for males. Level by age was the predominant medium, classified at this level $50.0 \%$ of students of 11 years, 53.8\% of students age 12 and $44.1 \%$ of students 13 years of age. Regarding the number of hours of use of online gaming as a result was obtained using $44.4 \%$ over 30 hours a week have a low degree of knowledge and a 33.3\% level of knowledge. Conclusion: A high percentage of students who do not know the effects of using online gamesA high percentage of students who do not know the effects of using online games.
\end{abstract}

Key words: Knowledge, games, internet. Peru. (Source DeCs BIREME).

Alumno de la Facultad de Enfermería. Universidad Peruana Cayetano Heredia. Lima-Perú

Licenciada en Enfermería. Docente de la Facultad de Enfermería de la Universidad Peruana Cayetano Heredia. 


\section{INTRODUCCIÓN}

Las sociedades actuales asisten a un creciente impacto de las nuevas tecnologías que vienen acompañadas de discursos que ensalzan sus efectos positivos, como de otros que denuncian los riesgos que implica su uso. Una de ellas, y la más controversial, es Internet, que brinda una amplia gama de transacciones antes inimaginables como el chat, las redes sociales, el correo electrónico y los juegos online. Estos últimos se han convertido en una de las actividades de ocio preferidas por los adolescentes, lo cual genera una creciente preocupación en los profesionales de la salud, padres de familia y educadores, aunado a los contenidos emitidos por este medio de entretenimiento y sus efectos en los usuarios y su entorno. Los juegos online son muy llamativos, pues están llenos de color, movimientos y acción, e integran, al mismo tiempo, el audio y el video, lo que permite al usuario disfrutar, desde un juego de destreza mental hasta uno de combate y aniquilamiento, pasando por las aventuras y el deporte. Se vuelven fascinantes y de extraordinaria relevancia para los adolescentes porque les permiten acceder a un mundo ficticio en el cual pueden experimentar diversas situaciones, que no vivirían en la realidad.

Según varios estudios de investigación se ha demostrado que los juegos online provocan diferentes efectos en sus usuarios, todo ello en relación directa con el tiempo y frecuencia de uso. Cabe recalcar que el adolescente se caracteriza por su susceptibilidad, ya que los cambios que presentan en esta etapa de vida en los aspectos físico, psicológico y social, implican grandes riesgos los cuales les son difíciles de superar. El informe técnico del Instituto Nacional de Estadística e Informática (INEI) comunicó que en el segundo trimestre de 2008, los adolescentes fueron los que más utilizaron Internet $(51,8 \%)$, siendo los servicios más visitados los juegos online; y según sexo, los varones son los mayores usuarios $(33,3 \%)$ en comparación con las mujeres $(25,9 \%)$ (1). Los juegos online generan mecanismos neurofisiológicos como la estimulación eléctrica de algunas regiones del encéfalo, que produce un efecto reforzador a través de las vías dopaminérgicas. Mientras que el usuario de los juegos online recibe una respuesta a su acción (ganancia o pérdida) cada cinco segundos, el jugador experimenta esta actividad dopaminérgica al hacer clic o teclear, acciones frecuentes (2).

En este sentido, y para el caso concreto, se señalan dos grandes tendencias a la hora de abordar la relación entre menores y nuevas tecnologías como los juegos online. Por un lado, autores que alaban las bondades tecnológi- cas y hacen hincapié en las posibilidades que ofrecen; por otro lado, todos aquellos que inciden fundamentalmente en los riesgos, amenazas y efectos negativos sobre los adolescentes; estos planteamientos que de una forma excesivamente determinista recogen la complejidad real de las relaciones de los usuarios con los videojuegos. De esta forma se apuesta por un análisis riguroso que tenga presente el contexto social en el que tales tecnologías se usan $\mathrm{y}$, por supuesto, las distintas formas en que son utilizadas. En los últimos años se han realizado estudios que partiendo de dicha complejidad tratan de lograr un mayor conocimiento de los riesgos reales y potenciales asociados al uso que los cibernautas hacen de las nuevas tecnologías. Así, entre otras estrategias, se recurre no solo a la opinión de expertos, progenitores o profesorado, sino a la de los propios protagonistas, tratando de ampliar el conocimiento sobre el uso real que estos hacen, y sobre los efectos negativos que los acompañan, evaluando la interpretación que ellos mismos desarrollan, siendo este grupo etario el que más usa los juegos online.

La adolescencia es una etapa del ciclo vital que posee características psicológicas, físicas y sociales inestables. Estas exigen del profesional de Enfermería una serie de competencias específicas que le posibiliten brindar un cuidado holístico y de calidad, tanto al usuario como a su familia, teniendo en cuenta el contexto en el que se desen vuelve. La Enfermería, al tener como objetivo básico el cuidado holístico de la persona, basado en evidencias científicas, nos motivó a realizar el estudio del siguiente problema de investigación: ¿Cuál es el nivel de conocimiento sobre los efectos de los juegos online en los estudiantes del primer año de educación secundaria de la Institución Educativa San Pedro Santísima Trinidad de Lurín en el año 2011? El objetivo fue determinar el nivel de conocimiento sobre los efectos de los juegos online en los estudiantes del primer año de educación secundaria, con el propósito de que los resultados de la investigación sirvan para contar con información que permita enriquecer las intervenciones de las enfermeras que se dedican al cuidado integral de los adolescentes, para mejorar el nivel de conocimientos sobre los efectos de los juegos online y así disminuir su uso excesivo.

\section{MATERIAL Y MÉTODOS}

El estudio fue de tipo descriptivo y de corte transversal, realizado en una institución privada que brinda sus servicios educativos en el nivel primario y secundario durante el turno de mañana, cuenta con una población aproximada de 1000 estudiantes y esta situada en San Pedro Santísima Trinidad en el distrito de Lurín, provincia de Lima, 
departamento Lima. La muestra es de 155 estudiantes de los cuales 33 pertenecían a primer año sección A; 34 primer año sección $\mathrm{B} ; 32$ al primer año $\mathrm{C} ; 23$ al primer año $\mathrm{D}, \mathrm{y} 33$ al primer año $\mathrm{E}$, los que cumplieron los criterios de selección. Para la recolección de datos se empleó un cuestionario autoadministrado, elaborado por las investigadoras, dividido en cuatro partes: I. Datos sociodemográficos; II. Conocimiento sobre los efectos físicos; III. Conocimiento sobre los efectos psicológicos, y IV. Conocimiento sobre los efectos sociales. Las preguntas correspondientes a los niveles de conocimientos se elaboraron de manera cerrada con cuatro opciones de respuesta y una verdadera a la cual se asignó el valor de 1 punto, con un puntaje total de 16, los que fueron clasificados según la escala de estanino en los siguientes niveles de conocimiento. Escala de clasificación 0 a 8 bajo; 9 a 13 medio, y 14 a 16 alto.

La validación del instrumento se realizó a través de juicio de expertos y prueba binomial donde se obtuvo como resultado 0,009769, lo cual indica validez de contenido al encontrarse que el error de significancia en el instrumento no supera los valores establecidos de p, el cual es un valor $\mathrm{P} d » 0,05$. $\mathrm{Al}$ analizar los resultados a través de prueba alfa de Cronbach se obtuvo un valor para el coeficiente de 0,649 , el cual, al ser superior a 0,6 constituye una evidencia de que el instrumento presenta confiabilidad. Luego de la obtención de la autorización por el director, docentes, padres y estudiantes y la firma del consentimiento informado, se procedió a recolectar la información, de manera anónima e individual. Al finalizar se entregó un tríptico con información de los efectos psicológicos, físicos y sociales de los juegos online. La aplicación del instrumento se realizó a los estudiantes de las cinco aulas en el mismo día, con una duración de 30 min por aula. Los datos fueron codificados e ingresados a una base de datos creada en Excel y analizados de manera porcentual.

\section{RESULTADOS}

En la tabla 1 se observa que el mayor porcentaje de los estudiantes tiene nivel de conocimiento medio, el 51,6\%, y el menor porcentaje tiene nivel de conocimiento alto, el $23,2 \%$. Además, el mayor porcentaje de los estudiantes del sexo masculino tiene el nivel de conocimiento medio, el $53,2 \%$ con tendencia a alto, el $29,9 \%$; y en el caso de las estudiantes de sexo femenino, el 50\% tiene nivel de conocimiento medio con tendencia a conocimiento bajo, el $33,3 \%$.

En la tabla 2 se observa que en los tres grupos de edades el mayor porcentaje de estudiantes tiene conocimiento medio. Los grupos de 12 y 13 años de edad tienen tendencia a conocimiento bajo, el 23,9 y $32,4 \%$ respectivamente. El grupo de 11 años edad tiene tendencia a conocimiento alto $(50 \%)$.

En la tabla 3 se observa que todos los grupos de estudiantes tienen un nivel de conocimiento medio, excepto los estudiantes que usan los juegos online más de $31 \mathrm{~h}$ a la semana, que tienen un nivel de conocimiento bajo $(44,4 \%)$. Además, se observa que el 56,8\% de estudiantes usa los juegos online entre 1 y $5 \mathrm{~h}$ a la semana y el $5,7 \%$ juega más de 31 horas a la semana.

Tabla 1. Nivel de conocimiento sobre los efectos de los juegos online en los estudiantes del primer año de educación secundaria según sexo. Lurín - Lima 2011

\begin{tabular}{lcccccc}
\hline \multirow{2}{*}{$\begin{array}{l}\text { Nivel de } \\
\text { Conocimiento }\end{array}$} & \multicolumn{4}{c}{ Sexo } & \multicolumn{2}{c}{ Total } \\
& N & \% & N & \% & \multicolumn{1}{c}{ N } & \% \\
\hline Bajo & 26 & 33,3 & 13 & 16,9 & 39 & 25,2 \\
Medio & 39 & 50,0 & 41 & 53,2 & 80 & 51,6 \\
Alto & 13 & 16,7 & 23 & 29,9 & 36 & 23,2 \\
Total & 78 & 50,3 & 77 & 49,7 & 155 & 100,0 \\
\hline
\end{tabular}

Tabla 2. Nivel de conocimiento sobre los efectos de los juegos online en los estudiantes del primer año de educación secundaria según edad. Lurín - Lima 2011

\begin{tabular}{lcrrrrr}
\hline \multirow{2}{*}{$\begin{array}{l}\text { Nivel de } \\
\text { Conocimiento }\end{array}$} & \multicolumn{9}{c}{ 11 años } & \multicolumn{2}{c}{ 12 años } & \multicolumn{2}{c}{$\mathbf{1 3}$ años } \\
& N & \multicolumn{1}{c}{ \% } & \multicolumn{1}{c}{$\mathbf{N}$} & \% & \multicolumn{1}{c}{$\mathbf{N}$} & \% \\
\hline Bajo & 0 & 0 & 28 & 23,9 & 11 & 32,4 \\
Medio & 2 & 50,0 & 63 & 53,8 & 15 & 44,1 \\
Alto & 2 & 50,0 & 26 & 22,2 & 8 & 23,5 \\
Total & 4 & 2,6 & 117 & 75,5 & 34 & 21,9 \\
\hline
\end{tabular}

En la tabla 4 se observa que el mayor porcentaje de los estudiantes ( $89,7 \%$ ), conoce que la cefalea es un efecto físico del uso de los juegos online. Y el mayor porcentaje de estudiantes desconoce que los juegos online tienen efecto sobre el aumento del ritmo cardiaco, el $67,7 \%$ y sobre la inflamación de los tendones de las manos, el 71\%.

En la tabla 5 se observa que el mayor porcentaje de los estudiantes conoce como efectos psicológicos del uso de los juegos online, el deterioro del rendimiento académico, $(92,3 \%)$ y la ansiedad $(91,6 \%)$; y en menor porcentaje conoce que la confusión y sustitución de la realidad por la ficción es un efecto psicológico del uso de los juegos online, $(54,2 \%)$. 
Tabla 3. Nivel de conocimiento sobre los efectos de los juegos online en los estudiantes del primer año de educación secundaria según horas de uso de los juegos online a la semana. Lurín - Lima 2011

\begin{tabular}{|c|c|c|c|c|c|c|c|c|c|c|}
\hline \multirow{3}{*}{$\begin{array}{l}\text { Nivel de } \\
\text { Conocimiento }\end{array}$} & \multicolumn{10}{|c|}{ Número de horas a la semana } \\
\hline & \multicolumn{2}{|c|}{1 a 5} & \multicolumn{2}{|c|}{6 a 10} & \multicolumn{2}{|c|}{11 a 20} & \multicolumn{2}{|c|}{21 a 30} & \multicolumn{2}{|c|}{$>31$} \\
\hline & $\mathbf{N}$ & $\%$ & $\mathbf{N}$ & $\%$ & $\mathbf{N}$ & $\%$ & $\mathbf{N}$ & $\%$ & $\mathbf{N}$ & $\%$ \\
\hline Bajo & 19 & 21,6 & 12 & 32,4 & 2 & 13,3 & 2 & 33,3 & 4 & 44,4 \\
\hline Medio & 46 & 52,3 & 19 & 53,4 & 8 & 53,3 & 4 & 66,7 & 3 & 33,3 \\
\hline Alto & 23 & 26,1 & 6 & 16,2 & 5 & 33,3 & 0 & 0 & 2 & 22,2 \\
\hline Total & 88 & 56,8 & 37 & 23,9 & 15 & 9,7 & 6 & 3,9 & 9 & 5,7 \\
\hline
\end{tabular}

Tabla 4. Conocimiento sobre los efectos físicos de los juegos online en los estudiantes del primer año de educación secundaria. Lurín - Lima 2011

\begin{tabular}{|c|c|c|c|c|}
\hline \multirow{3}{*}{ Efectos físicos } & \multicolumn{4}{|c|}{ Conocimiento } \\
\hline & \multicolumn{2}{|c|}{ Conocen } & \multicolumn{2}{|c|}{ No conocen } \\
\hline & $\mathbf{N}$ & $\%$ & $\mathbf{N}$ & $\%$ \\
\hline Total & 155 & 100,0 & & \\
\hline Sedentarismo & 113 & 72,9 & 42 & 27,1 \\
\hline Aumento del peso & 84 & 54,2 & 71 & 45,8 \\
\hline Aplazamiento del sueño & 75 & 48,4 & 80 & 51,6 \\
\hline Cansancio visual & 107 & 69,0 & 48 & 31,0 \\
\hline Cefalea & 139 & 89,7 & 16 & 10,3 \\
\hline Aumento del ritmo cardiaco & 50 & 32,3 & 105 & 67,7 \\
\hline Inflamación de los tendones de las manos & 45 & 29,0 & 110 & 71,0 \\
\hline
\end{tabular}

Tabla 5. Conocimiento sobre los efectos psicológicos de los juegos online en los estudiantes del primer año de educación secundaria. Lurín - Lima 2011

\begin{tabular}{lrrrr}
\hline \multirow{2}{*}{ Efectos psicológicos } & \multicolumn{2}{c}{ Conocen } & \multicolumn{2}{c}{ No conocimiento } \\
& N & \% & N & \% \\
\hline Total & 155 & 100,0 & & \\
Ansiedad & 142 & 91,6 & 13 & 8,4 \\
Adicción & 116 & 74,8 & 39 & 25,2 \\
Confusión y sustitución de la realidad por la ficción & 84 & 54,2 & 71 & 45,8 \\
Agresividad & 109 & 70,3 & 46 & 29,7 \\
Violencia & 120 & 77,4 & 35 & 22,6 \\
Deterioro del rendimiento académico & 143 & 92,3 & 12 & 7,7 \\
\hline
\end{tabular}

Tabla 6. Conocimiento sobre los efectos sociales de los juegos online en los estudiantes del primer año de educación secundaria. Lurín - Lima 2011

\begin{tabular}{lcccc}
\hline \multirow{2}{*}{ Efectos sociales } & \multicolumn{3}{c}{ Conocimiento } \\
& N & \% & No conocen & \% \\
\hline Total & 155 & 100,0 & & \\
Aislamiento social & 104 & 67,1 & 51 & 32,9 \\
Sustitución de relaciones familiares & 126 & 81,3 & 29 & 18,7 \\
Marginación & 85 & 54,8 & 70 & 45,2 \\
\hline
\end{tabular}


En la tabla 6 se observa que el mayor porcentaje de estudiantes tiene conocimiento de los efectos sociales de los juegos online. El 81,3\% conoce sobre la sustitución de relaciones familiares y el $67,1 \%$ sobre el aislamiento social

\section{DISCUSIÓN}

El 100\% de estudiantes que participó en el estudio usaban los juegos online; resultados similares a los encontrados en el estudio del año 2010 realizado por Bringué, Sábada y Tolsá, donde el $67 \%$ de encuestados de 10 y 18 años en el Perú, reconoce utilizar Internet para jugar en red (3); a diferencia de los resultados de un estudio realizado en Colombia en el año 2010, que encontró que el 40,1\% de adolecentes juega en red (4).

Como se puede apreciar, el porcentaje de estudiantes que usa los juegos online se ha incrementado en más del 30\%; dichos juegos captan cada día a más adolescentes usuarios, pues se encuentra que se promueve el uso de los juegos online desde los primeros años de la educación básica regular.

En relación al nivel de conocimiento los estudiantes obtuvieron nivel medio $(51,6 \%)$, con tendencia a conocimiento bajo $(25,2 \%)$. En los estudiantes del sexo masculino se encontró un nivel de conocimiento medio $(53,2 \%)$, con tendencia a alto (29,9\%), y en las estudiantes se halló que el 50\% tiene nivel de conocimiento medio con tendencia a conocimiento bajo $(33,3 \%)$ (Tabla 1$)$.

Resultados similares fueron encontrados en estudios de investigación realizados en Colombia y Perú en los años 2010 y 2011, donde los niños y adolescentes de sexo masculino usaban los juegos en Internet en mayor porcentaje que las de sexo femenino $(3,4)$. Asimismo, en otro estudio peruano realizado en el año 2011 por Arnao y Jiménez, se afirma que los videojuegos pertenecen a un universo masculino, el cual reafirman y reproducen permanentemente. Se trata de juegos diseñados por hombres y para hombres, según sus propios intereses y que, por consiguiente, ponen a disposición imágenes sobre los sexos y los roles correspondientes a ese particular punto de vista (5).

Como se puede apreciar, en el estudio realizado se evidencia un incremento de usuarias perteneciente, en una proporción similar a los usuarios de los juegos online; sin embargo, se observó que las estudiantes tienen un menor nivel de conocimiento sobre los efectos físicos, psicológicos y sociales.
En relación a la edad se encontró que en los tres grupos etarios, el mayor porcentaje de estudiantes tiene conocimiento medio; en los grupos de 12 y 13 años de edad tienen tendencia a conocimiento bajo, con el 23,9 y 32,4 respectivamente. Asimismo, se observó que el grupo de 11 años edad tiene tendencia a conocimiento alto (50\%), (Tabla 2). Un estudio realizado en Estados Unidos el 2010 señala que el $47 \%$ de encuestados entre las edades de 12 y 13 años hace uso de los juegos en Internet (6).

Como se puede observar, los juegos en línea se han convertido en la principal actividad de muchos niños y adolescentes y cada vez es menor la edad de inicio en el uso de los juegos online. Los 12 años es la edad de inicio más frecuente; no obstante que a esta edad los estudiantes mayormente desconocen efectos de dichos juegos, según los resultados encontrados. Respecto al nivel de conocimiento de los estudiantes según horas de uso de los juegos online a la semana, tienen mayormente nivel de conocimiento medio, excepto los estudiantes que usan los juegos por más de 31 horas a la semana, los cuales tienen nivel de conocimiento predominantemente bajo $(44,4 \%)$. Del mismo modo, se observó que el 56,8\% de estudiantes usa los juegos online entre 1 y 5 horas a la semana, y el $5,7 \%$ más de 31 horas a la semana (Tabla 3 ).

Resultados similares se encontraron en un estudio peruano del 2008; donde el 70,7\% de adolecentes dedicó entre 1 y 3 días a la semana al uso de los juegos online, el $29,3 \%$ le dedicó de 4 y 7 días y el 72,9\% le dedicó de 1 a $2 \mathrm{~h}$ al día (7). A diferencia de otro estudio realizado en el año 2011 , donde afirman que el $72 \%$ de la población encuestada usaba los juegos online entre 2 y $4 \mathrm{~h}$ al día y el $9 \%$ de la muestra juega más de $8 \mathrm{~h}$ al día. Además, el $47 \%$ del total contestó que juega entre 1 y 3 días a la semana, mientras que el $27 \%$ juega entre 4 y 5 días a la semana, y el 25\%, todos los días (5).

Con relación a los estudios anteriores, el número de horas y la frecuencia de uso de los juegos online se ha incrementado, habiéndose encontrado adolescentes que hacen uso de ellos por más de $31 \mathrm{~h}$ a la semana, los cuales, en su mayoría, desconocen sus efectos. Además, Cedro ha considerado los juegos online una nueva adicción no convencional (5), lo que vuelve este resultado aun más preocupante.

Respecto a los conocimientos de los estudiantes sobre los efectos del uso de los juego online, el mayor porcentaje de ellos $(89,7 \%)$, conoce que la cefalea es un efecto físico del uso de estos juegos. Y el mayor porcentaje de estudiantes desconoce sus efectos en el aumento del ritmo 
cardiaco $(67,7 \%)$ y en la inflamación de los tendones de las manos (71\%) (Tabla 4). Según Jaime Orrego las consecuencias relacionadas con el uso prolongado de los videojuegos online son la aparición de molestias en los ojos, con síntomas de irritación, al disminuir los movimientos de parpadeo que lubrican la córnea. También pueden presentarse dolores de cabeza frecuentes y dolores musculares ocasionados por malas posturas durante el juego. También se ha observado la aparición de molestias en las manos y muñecas, ocasionadas por tendinitis (8).

Muchos autores describen los diferentes efectos físicos y los riesgos que los niños y adolecentes experimentan debido uso de los juegos online. A pesar de la información brindada en los diferentes medios de comunicación, los adolescentes no conocen de estos efectos físicos, resultados que podemos constatar en el estudio. Con respecto al conocimiento de los estudiantes sobre los efectos psicológicos del uso de los juegos online se observó que el mayor porcentaje de ellos conoce como efectos psicológicos el deterioro del rendimiento académico $(92,3 \%)$ y la ansiedad (91,6\%); y en menor porcentaje conocen la confusión y sustitución de la realidad por la ficción $(54,2 \%)$, (Tabla 5).

Así se puede observar en un estudio realizado por Swing et al. en el que participaron niños y adolescentes, que la exposición a la TV y a los videojuegos estaba asociada con la aparición de problemas atencionales. Según Skosnik, et al., el mecanismo fisiológico que podría explicar este hallazgo es el aumento a la exposición de las hormonas del estrés, norepinefrina y cortisol (9). De igual manera, Gonzales señaló que estudios recientes sugieren que las fronteras entre los mundos virtuales y la realidad son mucho más porosas de lo que los expertos habían llegado a imaginar. Alrededor del $40 \%$ de los hombres y el 53\% de las mujeres que participan en mundos virtuales afirman que sus amigos virtuales son iguales o mejores que los amigos que tienen en el mundo real, de acuerdo a una encuesta realizada por la Universidad de Stanford (10).

Como se puede apreciar, los efectos psicológicos del uso de los juegos online han sido estudiados ampliamente por diferentes autores, pero estos efectos no son conocidos en similar proporción por los adolescentes usuarios de los juegos. Con respecto al conocimiento de los estudiantes acerca de los efectos sociales de los juegos online, se observó que el mayor porcentaje de estudiantes tiene conocimiento de sus efectos sociales $(81,3 \%)$, mientras que el $67,1 \%$ sabe sobre la sustitución de relaciones familiares y sobre el aislamiento social (Tabla 6).
En relación a los efectos sociales de los juegos online, un estudio encontró que el $53 \%$ de varones y el $51 \%$ de mujeres entre los 10 y 18 años de edad en Perú, hacen uso de los juegos online solos. Además, señaló que el $23 \%$ de los menores declara, la ausencia de cualquier acción o interés por parte de sus progenitores durante sus momentos de navegación por Internet (3). Coincidentemente, en la conclusión hallada en el estudio de investigación realizado por CEDRO, la ausencia del rol tutorial de los padres, sea por razones de trabajo, abandono o falta interés de ambos, genera que muchos adolescentes no cuenten con el apoyo cotidiano y constante de uno de sus progenitores, ocasionando así la falta de control parental, generando que Internet sea el nuevo espacio que reemplaza a la familia (5). Asimismo, en el artículo de revisión de Moncada y Chacón, señalaron que estudios de metaanálisis realizados por Anderson, et al. el 2010; Anderson, el 2004; Anderson Bushman, el 2001; y Sherry, el 2001, se encontró que la exposición a videojuegos violentos constituye un factor de riesgo causal para conductas agresivas y un comportamiento social reprimido, a pesar de que no se encuentran diferencias entre hombres y mujeres (9).

Los efectos sociales de los juegos online han sido también ampliamente estudiados, no obstante los resultados del presente estudio reflejan que éstos son también conocidos por los usuarios de los juegos online.

\section{REFERENCIAS BIBLIOGRÁFICAS}

1. INEI. Informe técnico: Las Tecnologías de Información y Comunicación en los Hogares 2009. [citado 12 Mar 2011]; disponible en: http:// www.inei.gob.pe/web/Boletin/Attach/8175.pdf

2. González A. La convergencia de los videojuegos o nline y los mundos virtuales: situación actual y efectos sobre los usuarios. [citado 10 Mar 2011]; disponible en http://www.ehu.es/zer/zer28/zer28-07.pdf

3. Bringué X, Sádaba C, Tolsá J. La Generación Interactiva en Iberoamérica 2010 Niños y adolescentes ante las pantallas [citado 20 Ene 2012]; disponible en http://www.generacionesinterac tivas.org/upload/libros/La\%20Generacion\%20 Interactiva\%20en\%20Iberoamerica\%202010.pdf

4. Arango G, Bringué X, Sádaba C. La generación interactiva en Colombia: adolescentes frente a la Internet, el celular y los videojuegos (revista en internet) 2010 [citado 20 Ene 2012]; disponible en http://www.generaciones interactivas.org/upload// libros/La\%20Generaci\%C3\%B3n\%20Interactiva\% 20en\%20Colombia.pdf 
5. Arnao J, Falla G, Jiménez A. CEDRO Los juegos en línea en adolescentes y jóvenes-Un estudio cuanti cualitativo descriptivo y analítico en jóvenes del Perú2011. [citado 22 Dic 2011]; disponible en: http:// www.cedro.org.pe/ Los_juegos_en_linea_en_ adolescentes_y_jovenes.pdf

6. Hamid, Mohsen, Abdollah, Babak M. RCesoearrcrhe alratictlees of video games playing among adolescents in an Islamic country 2010 [citado 21 Abr 2012]; disponible en (http://www.biomedcentral.com/content/ pdf/1471-2458-10-286.pdf).

7. Caldas J, Calderón N, Salazar V. Perfil de los adolecentes usuarios de los juegos online. [Tesis]. Lima: Universidad Peruana Cayetano Heredia; 2008.

8. Orrego J. Los niños y los videojuegos 2007 [citado 21 Abr 2012]; disponible en http://bibliotecadigital. icesi.edu.co/biblioteca_digital/bitstream/10906/44 92/ 1/139_ni\%c3\%b1os_videojuegos.pdf

9. Moncada J, Chacón Y. El efecto de los videojuegos en variables sociales, psicológicas y fisiológicas en niños y adolescentes 2012. [citado 21 Abr 2012]; disponible en http://www.retos.org/numero_21/ Retos\%2021\%2043-49.pdf
10. González A. La convergencia de los videojuegos online y los mundos virtuales: situación actual y efectos sobre los usuarios. 2011 [citado 10 mar 2011]; disponible en http://www.ehu.es/zer/zer28/zer2807.pdf

\section{Correspondencia}

Rosario Calle Sarmiento $4300345 / 985148007$

Correo electrónico: rosario_sarmiento@hotmail.com, rosario.calle@upch.pe

Forma de citar este artículo: Calle-Sarmiento R, Tafur-Núñez T, Ruiz-Huamán K, Villar-Prado S. Nivel de conocimiento sobre los efectos de los juegos online en los estudiantes del primer año de educación secundaria. Rev enferm Herediana. 2013;6(2):59-65. 